\title{
A EXPOSIÇÃO LETRADA: MOMENTOS E REFLEXÕES DE FOTOGRAFÍA EN LOS ANDES
}

\author{
Danielle Araújo ${ }^{1}$
}

\section{Introdução}

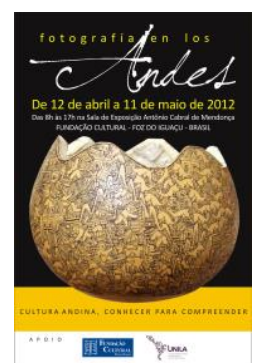

Fazer uma exposição sempre foi um momento de profundo questionamento. A imagem do Outro na exposição se torna foto de propriedade do fotógrafo. O mundo do Outro, universo particular, se torna uma pequena janela de observação, onde só um é visto. As pessoas que caminharam entre as fotografias expostas com seus olhares repletos de curiosidade e pré-conceitos, jamais serão vistas pelos fotografados.

A exposição diferente do ato fotográfico é uma monovia onde os fotografados se tornam objeto de observação. Na realidade só o fotógrafo sabe da relação e dos objetivos a cada clic. Durante a exibição das imagens, enquanto caminhavam, os observadores faziam uma série de colocações: que a foto está linda, bem ou mal enquadrada, clara, escura, comentários múltiplos, num jogo intrigante entre espectador e fotografia.

Uma questão elementar a ser salientada é que, em se tratando de fotos produzidas numa situação de pesquisa, a imagem nasce de interolhares construídos no momento da interação de dois ou mais sujeitos. Aquilo que poderíamos chamar de uma bela foto pode acontecer, mas não seria o objetivo final. No caso em questão posso afirmar com franqueza que nunca tive o propósito de produzir belas imagens. A obtenção das belas fotos não foi o foco do meu interesse, não era a intenção. A linguagem visual oferece possibilidades distintas de transmissão de conhecimento, tratase documento com interpretações múltiplas, daí a necessidade de esclarecer, por meio da escrita, as "reais" intenções dos fatos quando fazemos uma foto. O que denuncia a necessidade em escrever com imagens e figurar em palavras. Este relato escrito sobre os "olhares do olhar" ou a exibição pública de um ponto de vista vem da constatação que as imagens resultantes de uma investigação sem o suporte textual estão a mercê de interpretações equivocadas.

\footnotetext{
${ }^{1}$ Universidade Federal da Integração Latino-Americana, Brasil.
} 
Para Barbosa e Cunha (2006) "O antropólogo que lida com a imagem não pode, no entanto, destituir o olhar de sua força de significação. $O$ olhar capta o que pode significar, diferentemente da visão, que é competência física do corpo humano".

A imagem muitas vezes procura despertar sensações, compreensões que levem a conceitos, entendimentos num plano in e racional, que proporcionem tomadas de posições do sujeito, daí a importância do público em olhar com densidade, mergulhar na imagem em busca de uma sensação ou um entendimento.

Descortinar as situações e sentidos das imagens produzidas e apresentadas durante a exposição Fotografia en los Andes é o propósito desse artigo, que não nega a pretensão de ser uma espécie de exposição letrada, onde palavras e circunstâncias possam levar a formação de imagens e possivelmente questionamentos, assim como a desconstruções de noções previamente estabelecidas. No primeiro momento farei uma reflexão sobre o olhar estranhando do pesquisador, habitado por diferentes referenciais culturais e afetivos, no segundo momento discorro sobre as imagens no campo, abandonando minha empreitada com algumas observações sobre a exposição.

\section{O primeiro que (ins) escreve: o olho}

As fotografias que compuseram a exposição Fotografia en los Andes fazem parte de uma pesquisa de campo realizada, em 2007, no distrito de Pucará-Peru. Este distrito está localizado no altiplano peruano, Departamento de Lampa, na estrada que liga dois importantes centros turísticos: Cuzco e Puno. Nesta região se desenvolveu a cultura Pukara, que, assim como outros povos do chamado período pré-incaico, não possuiu documentos que narrassem sua passagem pelo Continente Americano. Por se tratar de uma civilização ágrafa, muitas informações sobre a forma de vida deste povo estão dispersas nos monólitos, na arquitetura dos templos e na cerâmica.

As pesquisas arqueológicas apontam que a civilização Pukara existiu há aproximadamente 2000 a. C e 400 d. C. Foi um dos maiores centros produtores de cerâmica da América Latina. Na ocasião da pesquisa meu objetivo foi analisar como a principal atividade econômica do lugar, a feitura da cerâmica, expressava a cosmovisão andina.

Em se tratando de um trabalho de campo, o olho é o primeiro que escreve. A Antropologia tem na observação sua primeira tarefa, antes de falar e perguntar, embora não negue que cada uma dessas funções possam ser desempenhadas com o olhar: 
primeiro olhamos. Trata-se de um olhar estrangeiro-estranhado; estranha o que vê e ao ser visto. $\mathrm{O}$ ato de olhar em si, instantaneamente, produz concepções, conceitos, ele não está destituído de estigmas e construções sociais, olhamos a partir de um ponto e a refração é resultando do lugar que ocupamos. Das inúmeras imagens produzidas durante a pesquisa é possível perceber a relação de aproximação, distanciamento, dúvidas diante do desconhecido. A motivação em cada foto varia do interesse em apreender a cena e ou encantamento que a situação provoca. O fato é que na chegada a qualquer lugar, primeiramente olhamos, o olhar é a primeira atitude de invasão e registro, olhamos sem pedir licença na certeza de que toda paisagem é pública. Não é à toa que em nome da segurança pública se alastra o uso das câmeras nas ruas, lojas e sinais de trânsito. Somos a sociedade do controle e nela a imagem como registro/prova é irrefutável e fundamental. A cena uma vez vista terá seus saberes registrados, revelados, um dito mudo da suposta verdade dos fatos.

O olho é o primeiro que in e escreve, fugir do imediatismo que este proporciona e os conceitos que ele nos traz são uma das primeiras armadilhas e desafios do antropólogo em campo. O exercício da reflexividade é algo importante na construção do olhar numa pesquisa, durante todos os momentos estamos exercitando os interolhares, interação que busca um diálogo.

Portanto, refletir sobre o uso da imagem, seja como metodologia de pesquisa, como material de analise, ilustração do texto, é um campo controverso, fértil e repleto de ambiguidade, um empreendimento ainda importante para as Ciências Sociais.

\section{Pesquisando com imagens}

Chapéu, casaco, protetor solar, câmera na mão, diário e caneta no bolso, o sol e o frio do altiplano arde. A aproximadamente $4.000 \mathrm{~m}$ acima do nível do mar, posso andar muito, mas não consigo correr nada. No caminhar diário a câmera foi minha confidente e companheira, com ela escrevi e dialoguei profundamente sobre o encontro com o Outro numa relação de pesquisa. Olhar e ser olhada, diálogo intersubjetivo, em menos de duas semanas conhecia muita gente e ao mesmo tempo era conhecida como $a$ moça que sempre anda com uma câmera fotográfica. Depois de quatro anos, teoricamente a pesquisa terminou, ainda visito Pucará anualmente, são pequenos momentos onde as discussões, queixas, se renovam em forma reprise/lembranças/imagens dos momentos vividos. De modo que a exposição, assim 
como a escrita desse ensaio, significa mergulhar num universo de imagens/sensações, escrita/itinerário.

Na pesquisa em Pucará o ato fotográfico procurou captar o sentido, o contexto de uma ação e ou acontecimento, uma ambiência onde os gestos, falas, sabores e odores criam um sentido que é conjugado com o texto.
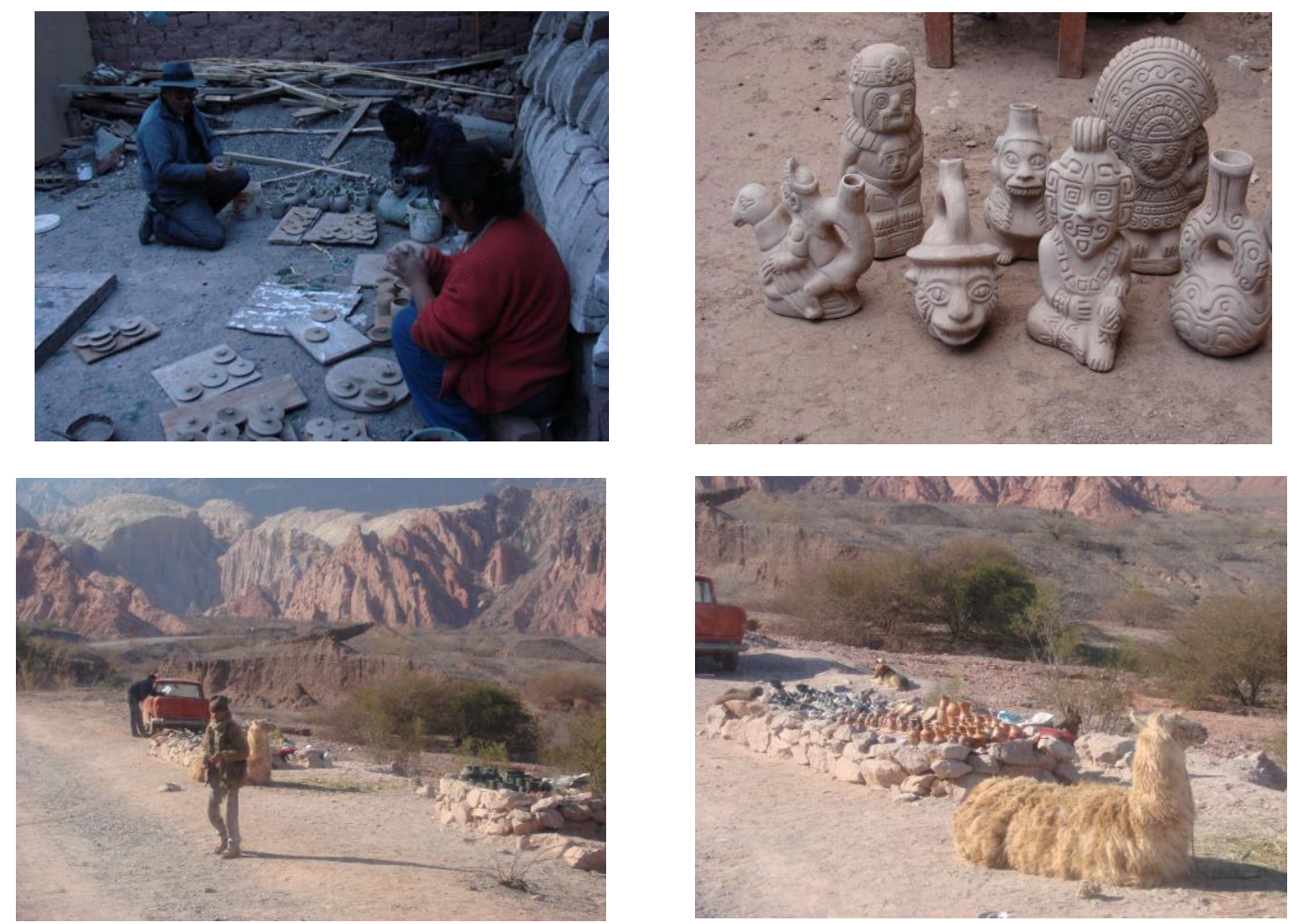

$* * *$

O propósito da pesquisa foi investigar a relação dos objetos de cerâmica com a cosmovisão andina, ou ainda como a materialidade dos objetos está repleta de imaterialidade. Os objetos de cerâmica são concebidos como imagens materializadas que vinculam concepções cosmológicas. Em Pucará eles (os objetos) relacionam, por 
meio de sua materialidade, esferas distintas, humanos e extra-humanos, ou seja, falam do visível e invisível.

A viagem rumo ao Peru saindo do Brasil pela via terrestre cruzando inúmeras fronteiras, caminhos de asfalto e terra, percorridos em mais de 20 dias, possibilitou a criação de um diário de imagens e palavras.

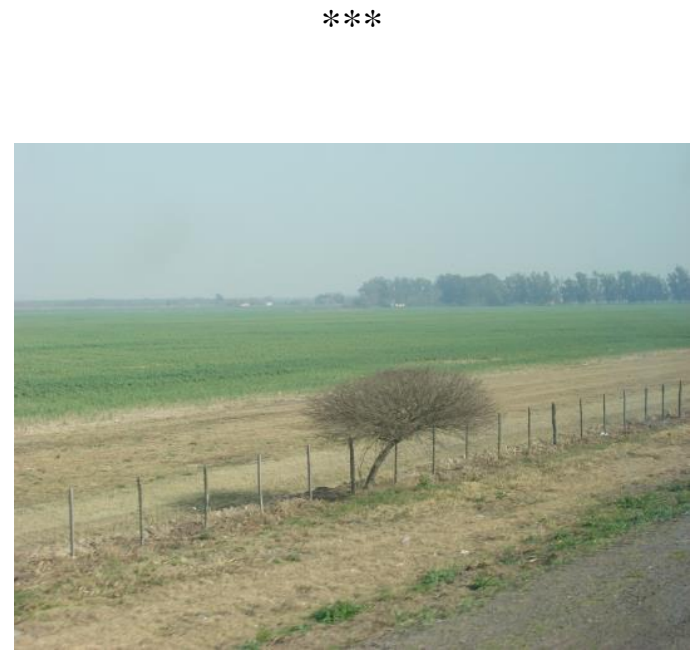

O olhar atento e questionador das nuances do caminho onde as paisagens foram concebidas como construções humanas possibilitou uma aproximação com a realidade cultural, social e econômica, imagens e vozes de uma latino-américa diversa e multifacetada.

A leitura da narrativa do espaço físico, lugares fugidios, que a lente da câmera fotográfica e a retina captavam, dava-me a sensação de uma colcha de retalhos que constituía uma lógica particular de cada região. Eram fragmentos de paisagens soando na composição de conceitos e categorias socioculturais. Recordei-me do mendigo na Praça de Mayo, em Buenos Aires, pedindo esmolas com uma placa escrita: soy del Chaco. Aos poucos, o que fora ouvisto, ganhava significados diferenciados; as partes se encaixando, produzindo novas combinações. Como diz o geógrafo Milton Santos, a transformação do todo, que é uma integral, em suas partes - que são as suas diferenças dá-se também por uma distribuição ordenada no espaço, dos impactos do todo, por meio de suas variáveis. É esse próprio princípio da diferenciação dos lugares, produzindo 
combinações específicas em que as variáveis do todo se encontram de forma particular (Santos, 2000: 100).

O lixo da estrada somado à aridez da terra faziam com que os cactos fossem esculturas em um território de aparente destruição. Os lugares eram espaços concretos de uma série de lutas e disputas que ecoam alegoricamente em jornais e manchetes: poluição do solo, do ar, falta d'água, fome, abundância, aspersores de água em dois quilômetros de propriedade privada; e um pequeno manto verde destoando da imensidão cinzenta.

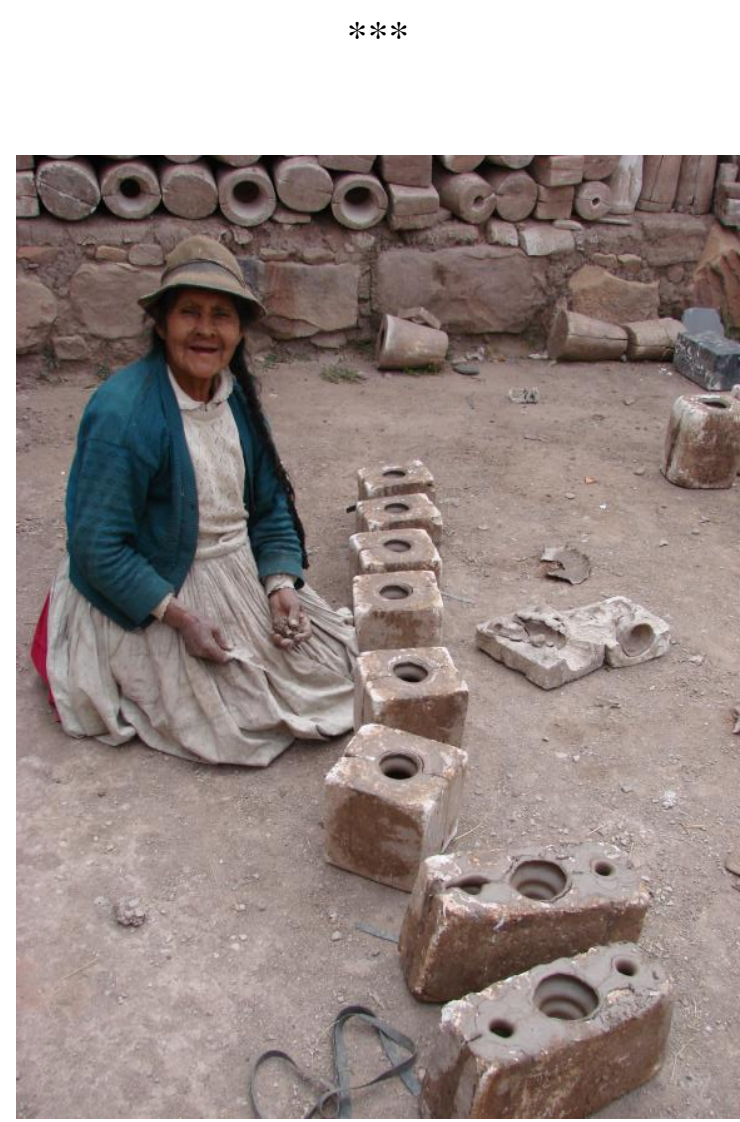

$* * *$

A paisagem produto humano mostrava-me as contradições dos territórios de um lugar para o outro, de um país a outro; as disparidades sempre foram frequentes. Estes lugares eram testemunhas silenciadas de ações políticas, compunham a tessitura dos embates. A elite portenha de Buenos Aires sempre negou os caciques dos povoados interiores; uma cultura negada, que precisava ser escondida (Lemos, 2006). O caminho mostrou-me espaços silenciados de pobreza e descaso. 
Paisagens, pessoas, vozes, mutismo, gritos, explosões, sabores e ruídos, tudo pode estar contido numa imagem. Apontar para a importância das imagens na construção da narrativa etnográfica, não desmerecer as falas e toda sonoridade da pesquisa. Como bem observam Cavignac \& Ciacchi (2006), "se eu vi, também ouvi". Os atos de fala e falas (Zumthor, 1993) dos informantes foram pontos de luz importantes na construção de muitas problemáticas. Em Pucará, entretanto, por mais paradoxal que possa parecer, a imagem destes 'fala' mais alto, pois, como fora recentemente colocado, os objetos, sejam eles artesanais ou não, são imagens materializadas. O etnógrafo na figura de produtor de imagens compõe com o visível uma narrativa particular imprescindível na elaboração do texto etnográfico.

A presença da câmera fotográfica em campo produzia uma série de fatos importantes que se tornaram pontos de reflexão. Em primeiro lugar, ela era uma espécie de distintivo de turista, pois afastava, uma vez que muitos não queriam ser fotografados. Por outro lado, aproximava, quando eu poderia ceder fotos. Assim foi com duas crianças de Pucará que me pediram dinheiro na praça. Expliquei-lhes que não daria dinheiro, mas a foto. Cumprida a promessa, passei a ser buscada para tirar fotos. Expliquei que não poderia dar todas as fotos que tirasse. Isso foi compreendido sem problemas.

As imagens no formato de fotografia, procuram também narrar o indizível e com ele tecer sentidos, onde as imagens e falas inscrevem, figurando aromas e sons que se complementam na inteligibilidade do texto.

A etnografia de qualquer natureza é rica em imagens e sons que nos afetam dos mais variados modos. As imagens conjugadas com texto recusam legendas, pois, elas possuem condição de interlocucionar.

Uma das interferências da imagem na produção etnográfica é na escrita etnográfica, o texto foi constituído tendo como base a constante re-visitação de inúmeras imagens que auxiliaram na lembrança de fatos e acontecimentos. O que também pode ser dito sobre o diário de campo e das gravações sonoras dos diálogos ou até mesmo do som ambiente, pois inúmeras vezes ao caminhar pelas ruas ou feiras acionava o gravador, a ponto de esquecê-lo - confesso. As inúmeras teses e dissertações que utilizaram as fotografias nas suas narrativas etnográficas, mostram que não há regras para o local do uso da imagem no texto, se no começo, meio, fim.

O ideal seria estar sempre exercitando nossa capacidade em idealizar palavras em sons e imagens, e ao revés, traduzir estas instâncias em textos provocando uma 
poética do devaneio, como nos diria Bachelard (1988). Nesta perspectiva seria o devaneio da imagem, sua obliquidade e imprecisão elementos fundamentais para a recriação na mente do leitor de uma mensagem outra que não estava no script, o problema na realidade seria a solução, pois a imagem imprime uma fantasia inevitável e muito bem-vinda ao texto. Afinal ela é muito mais do que de fato vemos, fotografamos aquilo que não vemos, e o que vemos pode assumir sentidos muito díspares do inicialmente intencionado/visto.

Para De France (1982), poderíamos dizer que quanto mais a antropologia se aproxima do material e do corporal, mais as imagens, estáticas ou não, encontram um campo fácil de expressão, o que facilitaria aos etnógrafos transpor em imagens as suas problemáticas de pesquisa, na medida em que elas teriam uma visibilidade própria. Entretanto, à medida que os etnógrafos passam a investigar a invisibilidade do pensamento e das representações coletivas que perpassam e dão sentido à vida social, menos expressão visual seus problemas de pesquisa vão ter. Quanto mais os antropólogos trabalham sobre a fala, sobre as narrativas, em busca dos significados, mais difícil é transformar essas falas e as categorias que elas articulam em imagens.

Pensar no fazer etnográfico com imagens significa a todo momento tentar captar o indizível, e com ele dizer, assim como em alguns momentos é impossível falar com imagens, em outros momentos me parece imprescindível. As imagens e as falas gravadas procuram captar e expressar a latência do campo sob a perspectiva do pesquisador. No texto, a escrita coopera com a imagem, transcreve a fala, procura, mediante esses elementos, ambientar uma paisagem de cores, texturas, sabores e sensações que traduzam o encontro etnográfico.

\section{Exposição: Fotografía en Los Andes}

A exposição foi realizada na Fundação Cultural de Foz do Iguaçu, um dos poucos espaços na cidade que permitem a realização de eventos desse tipo, embora, não disponha de condições ideais, pois não possui sala de exposição com iluminação e/ou suportes adequados. Foram expostas aproximadamente 25 fotografias de 50x80, o objetivo era apresentar a Foz do Iguaçu um Outro distante geográfica e culturalmente, trazer mais diversidade à fronteira, além de contribuir com uma das missões da Universidade Federal da Integração Latino-americana - UNILA, que tem como um de seus pilares a integração da América Latina. 
Como citei no início desse ensaio, fazer uma exposição é algo intrigante, seria a exposição uma forma de retorno do trabalho à comunidade ou mais uma estratégia que, de um certo modo, enaltece o pesquisador/fotógrafo.

A exposição, da montagem à abertura, apostou no encontro entre desconhecidos. $\mathrm{Na}$ entrada do salão, onde estavam as fotos, montamos uma espécie de portal com mantas peruanas; um pequeno símbolo de que as pessoas estavam passando para um universo com uma lógica distinta. A abertura seguiu com a recitação de poemas em quêchua por alunos peruanos e bolivianos, seguida da exibição de um videopoema. Após estas performances as luzes do salão foram ligadas, enfim chegamos à exibição das fotos

A particularidade dos Andes e o estranhamento e, ao mesmo tempo, admiração foram evidentes e expressas em falas, os espectadores, enquanto olhavam, falavam de impressões e sensações que a foto provocava, em alguns momentos não parecia ser a imagem uma representação, mas a própria realidade, posta num quadro 50x80, um portal do tempo e espaço, que levava aos Andes. Algumas pessoas perguntavam quanto tempo estive lá, outros diziam conhecer, afirmavam que agora iriam ao Peru, referência aos pontos turísticos como Machu-Picchu, Lago Titicaca nunca faltaram.

Sobre a temática das fotos procurei narrar sobre o cotidiano, esse invisível, pessoas nas feiras, nas ruas, pouca ênfase aos personagens e foco no contexto da ação, momento em que a vida transcorre sem nos darmos conta.

Fotografar o cotidiano pode parecer uma tarefa fácil, mas inegavelmente é repleta de armadilhas, o cotidiano não é feio ou bonito, ele é o pulsar de uma intensidade outra que chamamos de vida, que beira da sensatez à desordem. Falar do Peru no Brasil e não recorrer à exuberância dos pontos turísticos ou à pobreza extrema, é um ato arriscado, pois estamos acostumados aos estéreos-tipos que inundam a retina. Logo a exposição Fotografía en Los Andes trouxe aos moradores da fronteira, como poderia ter levado a qualquer outro lugar do Brasil, um Peru desconhecido, componente Latino-americano pouco visto e habitual em telas. A realização deste tipo de ação é um traço que questiona as perspectivas edificadas.

As indagações acerca do retorno ou não das pesquisas é enfático quando se trata de imagens. Nós que realizamos nossas escritas com imagens somos sempre questionados com uma ênfase adicional, sobre o retorno do trabalho. O retorno da pesquisa aos nossos interlocutores é algo inquestionavelmente importante, porém quando a ênfase recai sobre o uso da imagem, identifico as centelhas do preconceito 
sobre o uso das imagens, em detrimento ao edifício da escrita. A Academia durante sua história secular edificou seus saberes formando mestres e doutores sobre a espinha dorsal de grupos excluídos. A escrita neste contexto de iletrados foi, como ainda muitas vezes é, a expressão máxima de tornar o outro alheio. O registro da escrita, apesar da importância acadêmica, muitas vezes não levou aos grupos um real retorno, isto ainda é muito pouco questionado. Em câmbio o uso da imagem recebe duras críticas: tirar fotos, invadir e guardar a imagem parece ser mais pecaminoso do que registrar escrituralmente.

A crítica sobre o retorno da pesquisa deveria ser um ponto nevrálgico de toda pesquisa; em se tratando da antropologia, uma dor crônica, pois, por mais contraditório que possa parecer, a pesquisa não termina quando acaba. O que termina são os financiamentos, prazos, compromissos institucionais, mas a relação com o grupo, com as realidades traduzidas, pessoas que nos ajudaram num processo lento de transformação em campo, este compromisso permanece aberto ao tempo.

\section{Referências}

ACHUTTI, Luiz Eduardo Robinson. Fotoetnografia da Biblioteca Jardim. Porto Alegre: Editora da UFRGS; Tomo Editorial, 2004.

BACHELARD, Gaston. A poética do devaneio. São Paulo: Martins Fontes, 1988.

BARBOSA, Andréa; CUNHA, Edgar Teodoro da. Antropologia e Imagem. Rio de Janeiro: Jorge Zahar, 2006.

CAVIGNAC, Julie. "Vozes da tradição: reflexões preliminares sobre o tratamento do texto narrativo em antropologia". In: Horizontes antropológicos, 12. Porto Alegre: UFRGS, 1999. p.245-265. (Mneme - Revista de Humanidades [On-line]). Disponível em: http\\ www.seol.com.br \meme. Acesso em 28 de fev. 2008.

FRANCE, Claudine de. Cinémas e anthropologie. Travaux et documents. Paris: Maison des Sciences de l'Homme, 1982.

LEMOS, Amália Inés Geraiges de; SILVEIRA, Maria Laura; ARROYO, Mônica, (org.). Questões territoriais na América Latina. $1^{\mathrm{a}}$ ed. Buenos Aires: Consejo Latinoamericano de Ciências Sociales-CLACSO; São Paulo: Universidade de São Paulo, 2006.

SANTOS, Milton. A Natureza do Espaço - técnica e tempol razão e emoção. São Paulo: Hucitec, 1996. 